\title{
Combined Qualification Vibration Testing and Fixed Base Modal Testing Utilizing a Fixed Based Correction Method
}

\author{
James P. Winkel, Vicente J. Suárez, and James C. Akers \\ NASA Glenn Research Center \\ 21000 Brookpark Road \\ Cle veland, Ohio 44135
}

\begin{abstract}
Vibration testing spaceflight hardware is a vital, but time consuming and expensive endeavor. Traditionally modal tests are performed at the component, subassembly, or systemlevel, preferably free-free with mass loaded interfaces or fixed base on a seis mic mass to identify the fundamental structural dynamic (modal) characteristics. Vibration tests are then traditionally performed on single-axis slip tables at qualification levels that envelope the maximum predicted flight environment plus $3 \mathrm{~dB}$ and workmanship in order to verify the spaceflight hardware can survive its flight environment. These two tests currently require two significantly different test setups, facilities, and ultimately reconfig uration of the spaceflight hardware. The vision of this research is to show how traditional fixed-base modal testing can be accomplished using vibration qualification testing facilities, which not only streamlines testing and reduces test costs, but also opens up the possibility of performing modal testing to untraditionally high excitation levels that provide for test-correlated finite element models to be more representative of the spaceflight hardware's response in a flight environment. This paper documents the first steps towards this vision, which is the comparis on of modal parameters identified from a traditional fixed-based modal test performed on a modal floor and those obtained by utilizing a fixed based correction method with a large single-axis electrodynamic shaker driving a slip table supplemented with additional small portable shakers driving on the slip table and test article. To show robustness of this approach, the test article chosen is a simple linear weldment, whose mass, size, and modal parameters couple well with the dynamics of the shaker/slip table. This paper will show that all dynamics due to the shaker/slip table were successfully removed resulting in true fixed-base modal parameters, including modal damping, being successfully extracted froma traditional style base-shake vibration test setup.
\end{abstract}

Keywords: modal testing, pretest analysis, model updating, base-shake, environmental testing, fixed base

\section{INTRODUCTION}

Testing spaceflight hardware is a vital, but time consuming and expensive endeavor. Traditional dynamic test methods presently require two separate tests; the first, a modal test performed on a seismic mass, and the second, a flight level verification test performed on a shaker table. The vision of this research is to combine two separate structural dynamic tests required for space hardware verification into one, which would allow performing modal testing to untraditionally high excitation levels that could approach flight levels.

Several different methods have been proposed to extract fixed base modes from structures mounted on shake tables [1]-[9]. Authors of this paper were able to be involved with utilizing one of these methods developed by ATA Engineering, which utilizes the shake table accelerations as references when calculating the Frequency Response Functions (FRFs) [8]-[9]. It is the intent of this research to start where these two papers left off and further advance utilization of these methods.

Currently only the first stage of a multi-phase research effort has been completed. This paper discusses the test setup, trade studies performed prior to the testing on the shaker table, describing the challenges and lessons learned thus far, and finally disclosing the plan for completing the remaining two phases of the research effort. In the next phase, the primary objective 
will be to process all the data collected in the first phase and formulate a test plan that incorporates any necessary ch anges. In the third and final phase, the plan will be to carry out high level vibration testing and extracting fixed based modal parameters from this same test.

\section{SIMPLE BEAM PATHFINDER STUDY}

As a pathfinder to verify that the methodology of using accelerations as references to remove base motion was being properly implemented, a simple free-free beam was used [10]. The setup of this simple free-free beam involved a 2" square 6061-T6 aluminum hollow rectangular cross-section beam that was 87 " long and had a wall thickness of 0.125 " thick. As shown in Figure 1, the beam was suspended froma 1 ton overhead crane hanging over 12 feet above thetop of the beam. A thin nylon string was used directly tied to the top of the beam. In between the string and the chain of the hoist, a rubber bungee cord was added to is olate any modes from the crane influencing the beam as well as lower the rigid body suspension modes of the beam to frequencies much lower than the flexible body mode frequencies to simulate a free-free boundary condition.
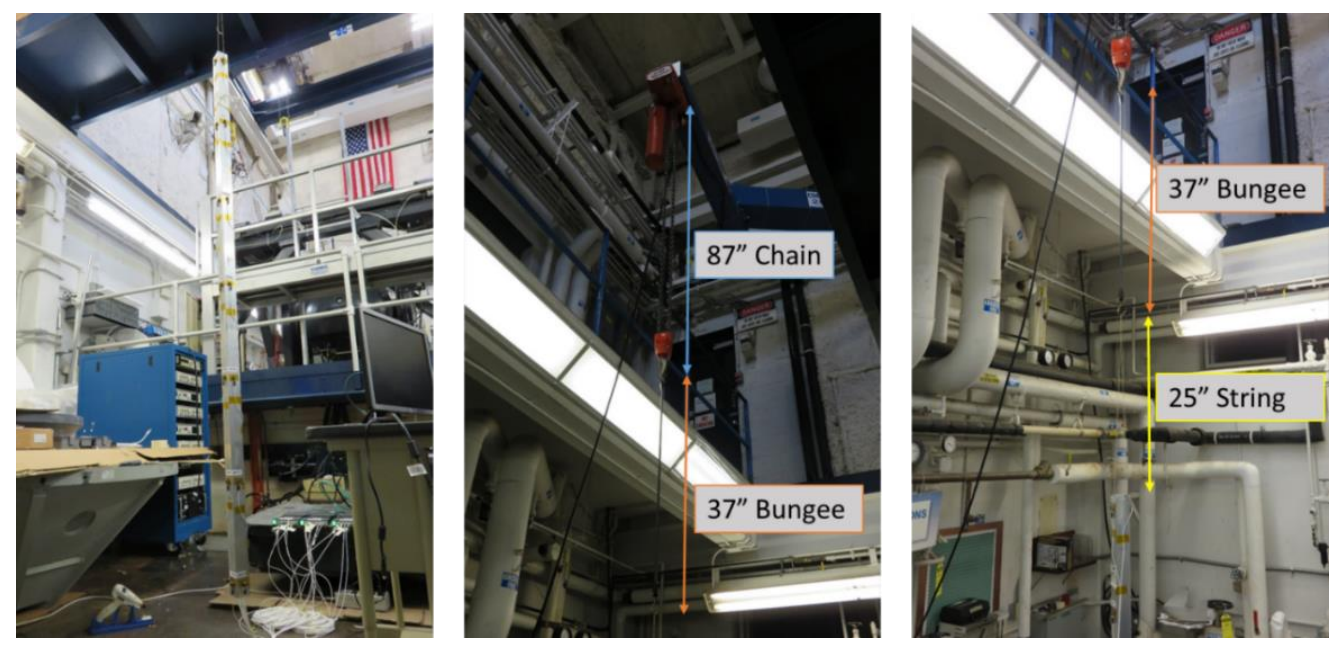

Figure 1. Simple Beam Pathfinder Setup

The beam was divided into six equal sections and 7 uniaxial accelerometers were placed along the beam in each of the two lateral beam directions. A single uniaxial accelerometer was placed at the top of the beamoriented in the axial direction to be able to measure motion along the beams axial direction. This totaled up to 15 channels of accelerometer data for the test. A small impact hammer with a white vinyl tip was utilized for the excitation. A total of 10 impacts were collected at each of the 15 accelerometer measurement locations.

The method was exercis ed to verify that the modal parameters of this simple beam with the following three restrained boundary conditions: pinned at one end, pinned at bothends, and pinned at the ends as well as in the middle, could be extracted fromits free-free modal hammer survey. A finite element model (FEM) was generated utilizing 2D beam elements with a total four boundary conditions, the free-free boundary conditions of the test and the three restrained boundary conditions. The first four FEM modal frequencies and mode shapes of the four boundary conditions were computed and compared to the modes extracted using the fixed-base method and are shown in Figure 2.

Time his tories were post processed into frequency response functions (FRF) by concatenating the impact hammer data into one long time his tory file depending upon the specific locations needed to extract the desired boundary condition. For example, in simulating the boundary condition of the beambeing pinned at bothends, the impact time his tories for the $\mathrm{X}$ (lateral) directions at both end location were concatenated together. Then the time his tories were post processed using drive point accelerations at those impact locations as references. The Hv FRF method was utilized due to the fact that the noise levelon the reference accelerometer and response accelerometer was equal in magnitude. Comparis ons of the FEM and extracted fixed-base frequencies and a visual ins pection of the FEM and extracted fixed-base mode shapes was performed and are shown in Figure 2. Figure 3 illus trates the cross orthogonality comparison between the FEM and test results for these different boundary 
conditions. This study verified that a fixed-base correction technique, in this specific case using drive point accelerometers as references, could be used somewhat effectively to extract modal parameters for different boundary conditions from a free-free modal test. It was definitely more difficult to extract clean modes shapes when the boundary conditions the test data was being corrected to became more complicated. Thus, when trying to simulate the pinned-pinned-pinned condition, while the deformation shapes and frequencies appeared to be correct, the cross-orthogonality was not as clean. More work is planned to be done using this data to help make more significant conclusions. It is the hope that prior to using any other fixed based correction techniques on the shaker slip table, these techniques can first be applied to this simple free-free beamdata.

There were a few challenges encountered with the setup of this pathfinder study that if it were redone would be avoided. The test article had a symmetric square cross-section meaning that there were two lateral bending modes at each res onant frequency, which were aligned with the axes of the cross-section and therefore occurring in orthogonal planes to each other. The closely spaced and highly similar mode shapes made it much more difficult to extract the modes cleanly. The second was that running all the accelerometer cables taped down the length of the beam created a significant amount of mass loading and additional damping. This study is far from being fully completed and the hope is to spend more time with this data going forward.
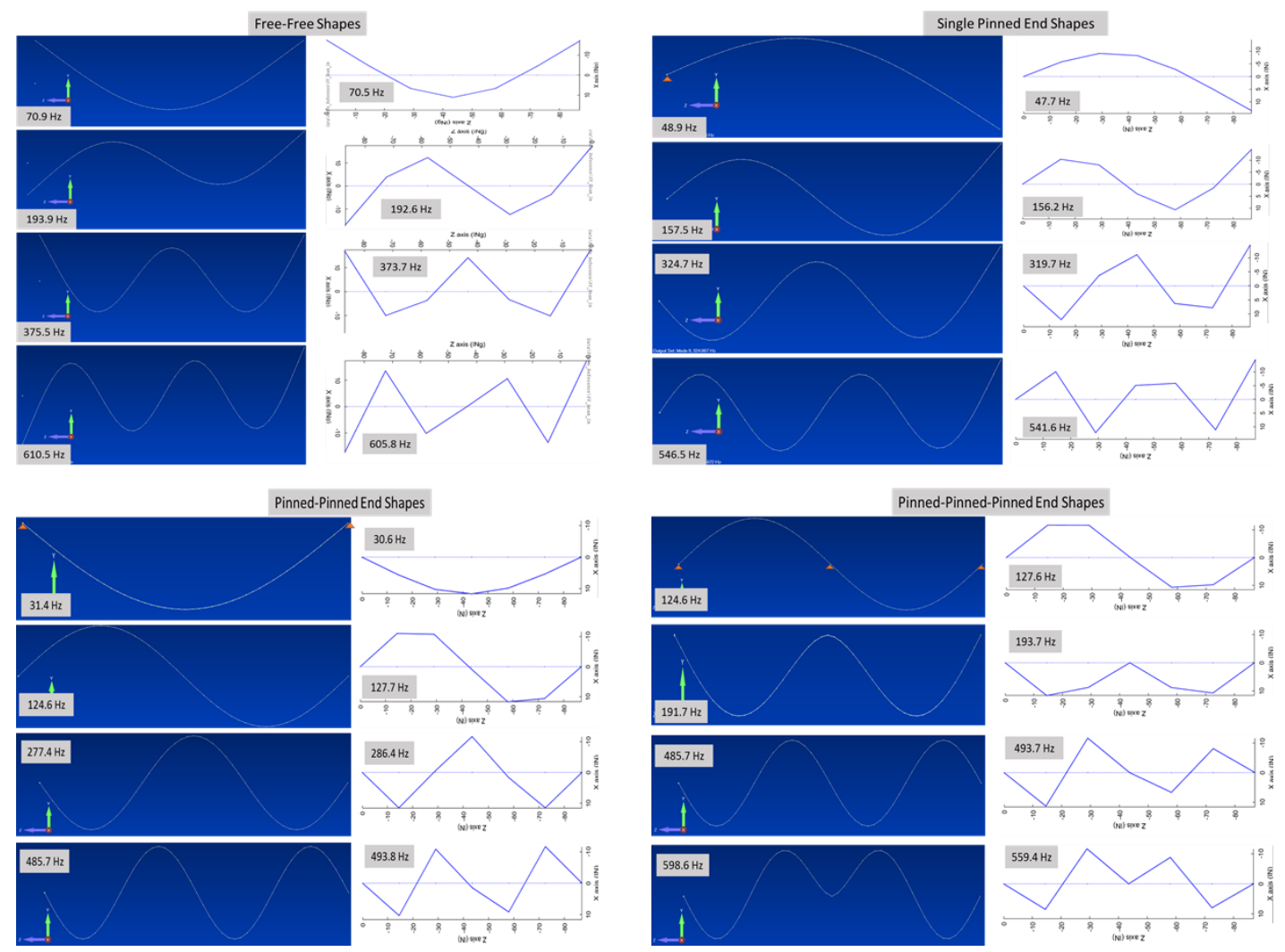

Figure 2. Simple Beam Pathfinder Fixed Based Correction Mode Shape and Frequency Comparis on 
Free-Free

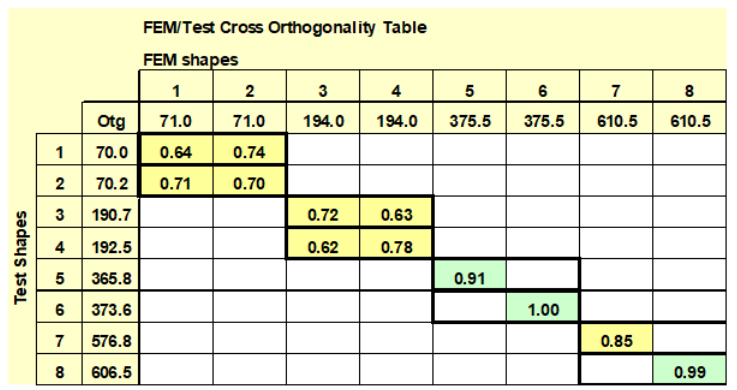

Pinned-Pinned

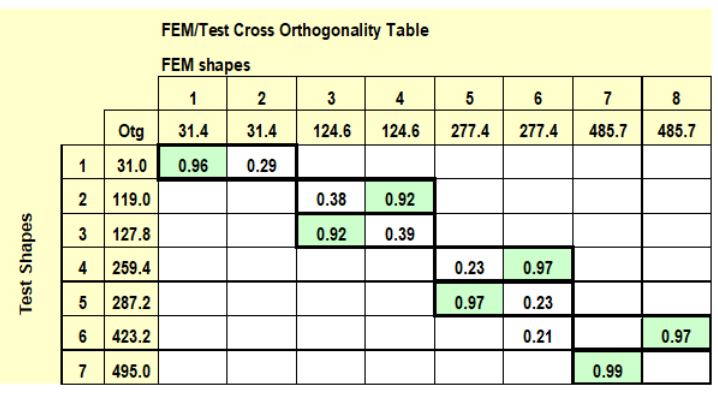

Single-Pinned

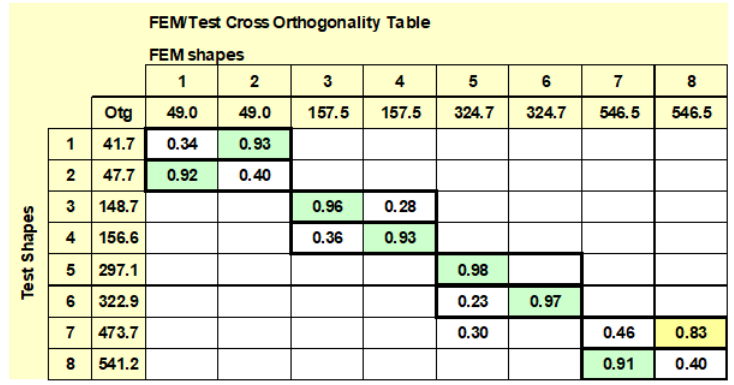

Pinned-Pinned-Pinned

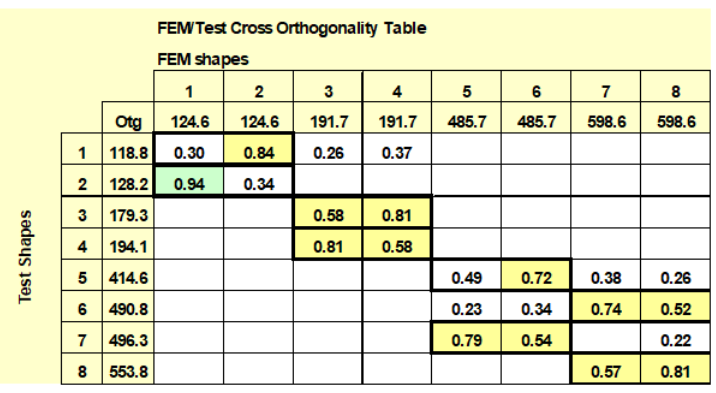

Figure 3. Simple Beam Pathfinder Fixed Based Correction Cross-Orthogonality Comparison

\section{TEST ARTICLE SELECTION}

For the first stage of this research, development of an appropriate test article along with all the infrastructureneeded to perform the modal testing was the first step. Initially, it was planned that a test article would be designed and fabricated that would meet the following requirements: simple design and fabrication, behave linearly, have sufficient weight to influence the current shaker table dynamics, and have its fundamental lowest frequency modes in the same frequency range as most aerospace structures. Shortly into the process, it became clear that meeting all these requirements would be cost prohibitive and would exceed the first stage schedule constraints. As a compromise, an exis ting magnesiumbookend used in the dynamics lab was chosen because it would meet the first three requirements. However, unfortunately its lowest fundamental modes are significantly higher in frequency than typical aerospace test articles. At the time it was felt that this limitation would not be an is sue for the first stage of this res earch effort.

The magnesiumbookend weighed 217 pounds and was expected to behave extremely linear since it was a fully welded magnesium structure. The bookend utilized $3 / 8$ inch diameter fasteners in a 4 inch $x 4$ inch square hole pattern to hold it down to the floor. More detailed information on the article can be seen in Figure 4.
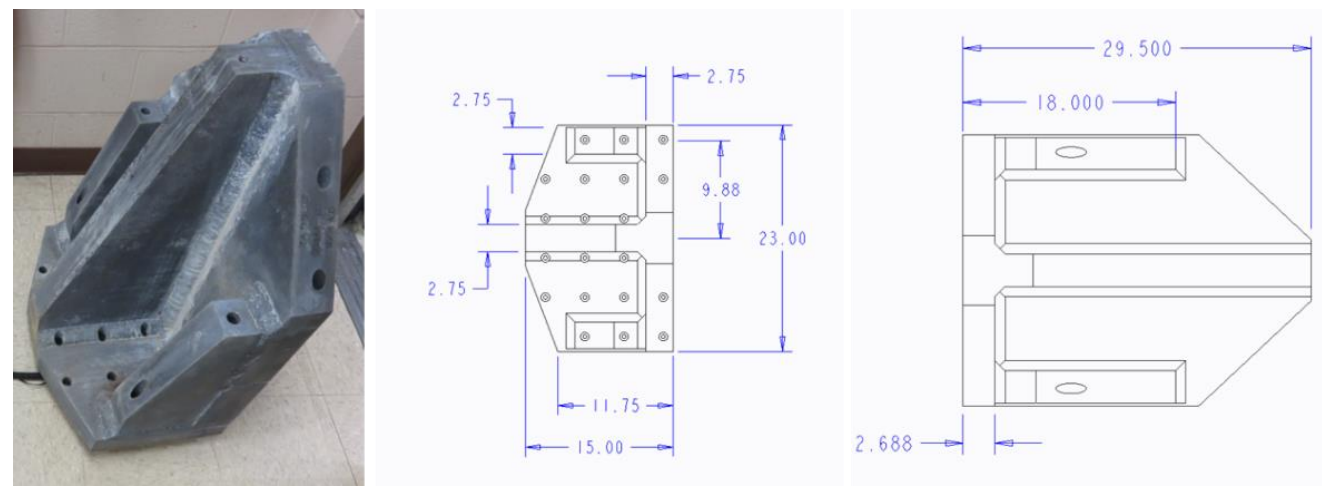

Figure 4. Selected Test Article 


\section{FEM CONSTRUCTION AND SENSOR PRETEST TRADE STUDY}

A FEM of this magnesium bookend was created to support this research effort. Three different FEMs of the bookend were generated using three different modeling techniques traditionally utilized in modeling aerospace structures. The first, and most simple, modelling technique was to model the bookend using 2D shell elements over the entire bookend, which is typically done in aeros pace loads FEMs, and is shown in Figure 5 and will be referred to throughout this paper as the Simple 2D Shell FEM. The advantages of this type of FEM are it is the simplest FEM to generate, analyze, modify, and it has the shortest solution runtimes. The dis adv antage of this modeling technique is that simple features such as holes and welds are not taken into account and there is a lot of duplication of mass at the joints, which was especially the case due to the extreme thickness of the plates.
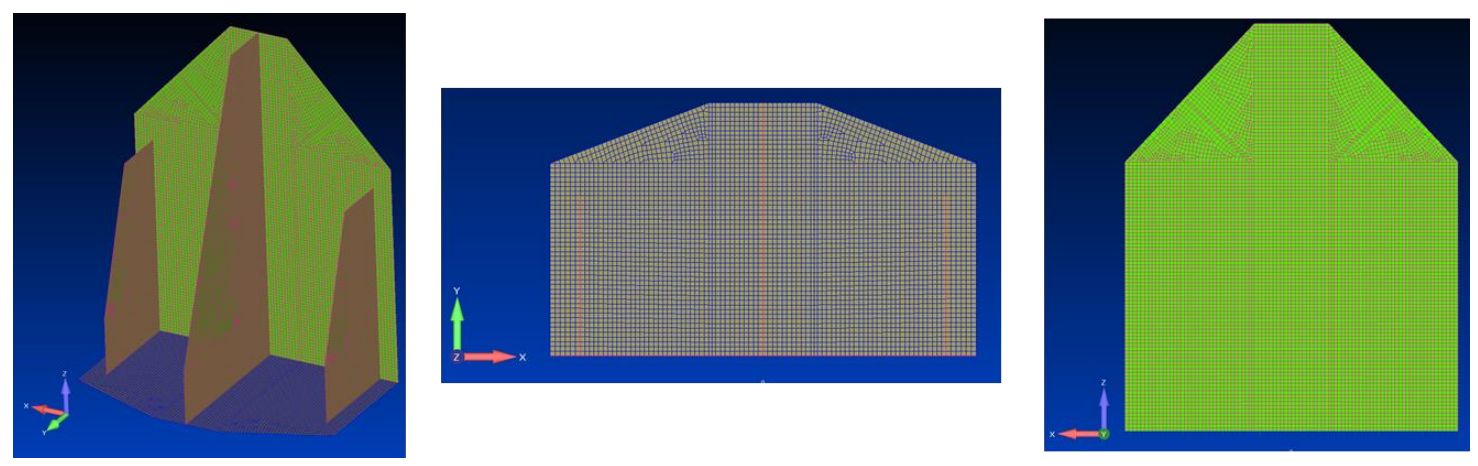

Figure 5. Simple 2D Shell FEM

The second modelling technique utilized was to automesh the CAD representation of the bookend using 3D solid tetrahedral elements, which has the advantage that very fine detail can be accurately captured. The obvious dis advantages of this technique is that solution run times are significantly longer and trying to modify or troubleshoot the FEM can be extremely cumbersome given the number of elements and nodes that are internal to the outer surface and not easily sorted out. The bookend FEM utilizing this second modelling techniqueis shown in Figure 6 and will be referred to as the Solid 3D FEM.
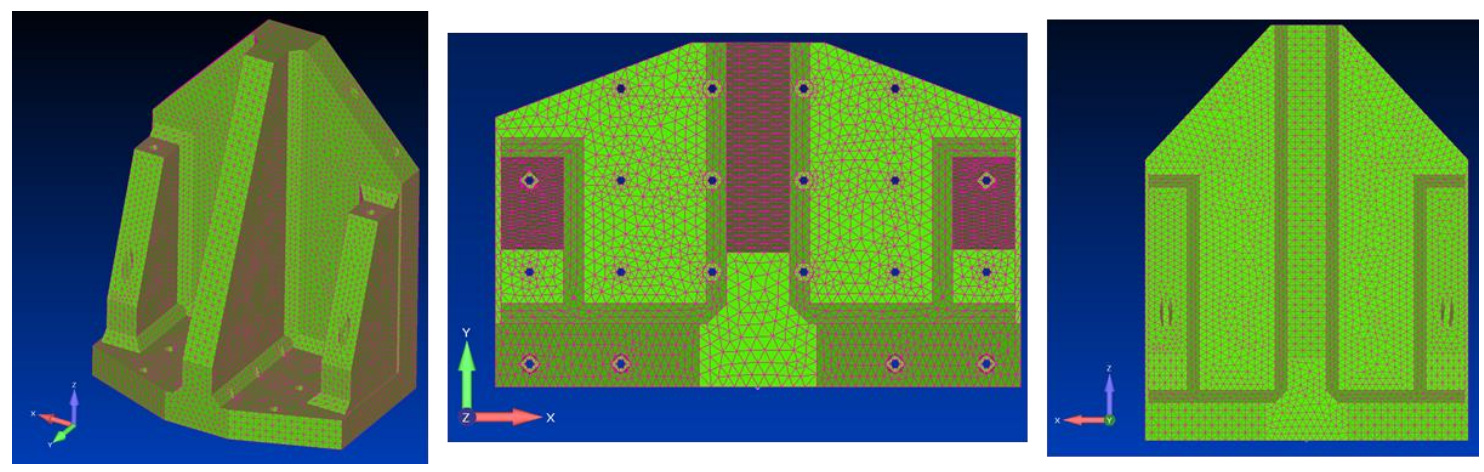

Figure 6. Solid 3D FEM

The final modelling technique used is a hybrid approach where the starting point was the simple 2D shell FEM and then making modifications to eliminate the overlapping elements at joints and adding in more detail to capture details such as holes and welds. Element offsets and RBE2 spider elements are utilized the make this added detail possible. The advantages of this modeling technique is it allows for the increased accuracy of the mas s distribution and stiffness changes without going to the full extreme of solid elements. However, the dis advantage is it is the most difficult and time consuming FEM to create. The bookendFEM utilizing this third modelling technique is shown in Figure 7 and will be referred to throughout this paper as the Complex 2D Shell FEM. 

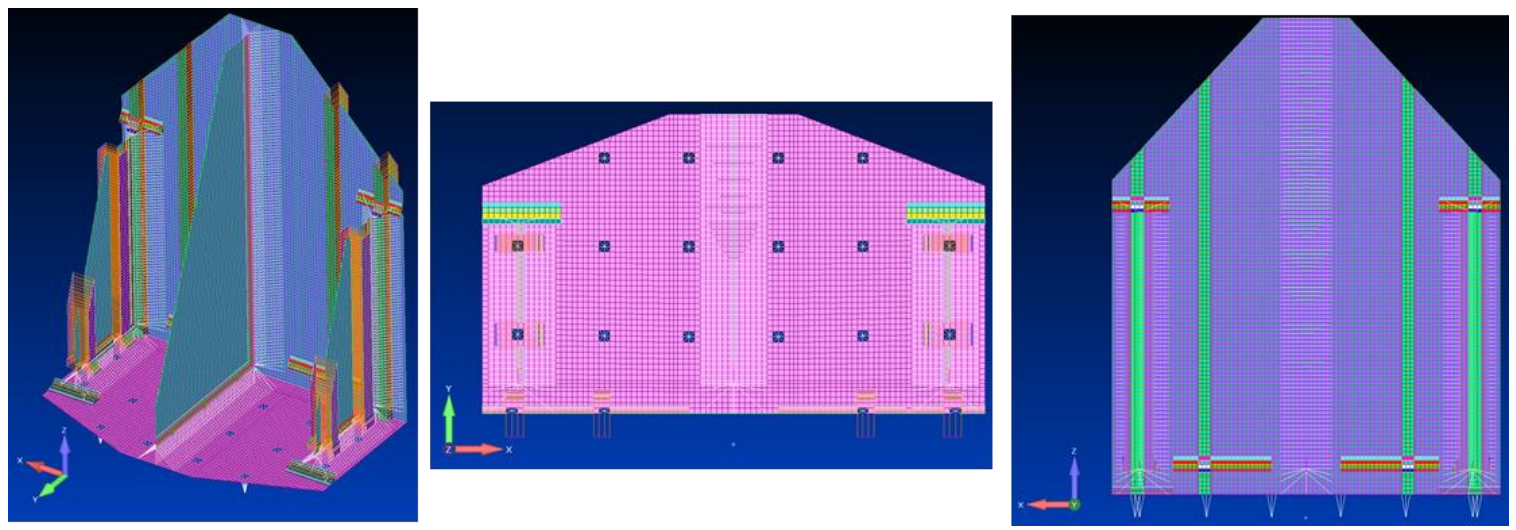

Figure 7. Complex 2D Shell FEM

At this point, the reader may be wondering why three differentFEMs were created for this research. It was done as a side study to allow test engineers to ability to investigate which finite element modeling technique would most closely match the real dynamics of the bookend. In the process of finding out the answer to this, test engineers could also look into which FEM modeling technique would be the most efficient to utilize in modal pretest analyses which are done to see how many accelerometers are required to independently capture the target modes. Modal pretest analysis was performed utilizing a customized set of MATLAB-based testDOF selection tools thatdraw extensively upon ATA Engineering's IMAT® software packages. A simple CBUSH spring was attached to the top of the bookend representing the test verified axial stiffness of a bungee cord that would be used to hold the bookend suspended in the subsequent modal survey. The first nine elastic body modes for each FEM (i.e. the 6rigid body suspension modes were excluded) were used as target modes in these pretest analyses.

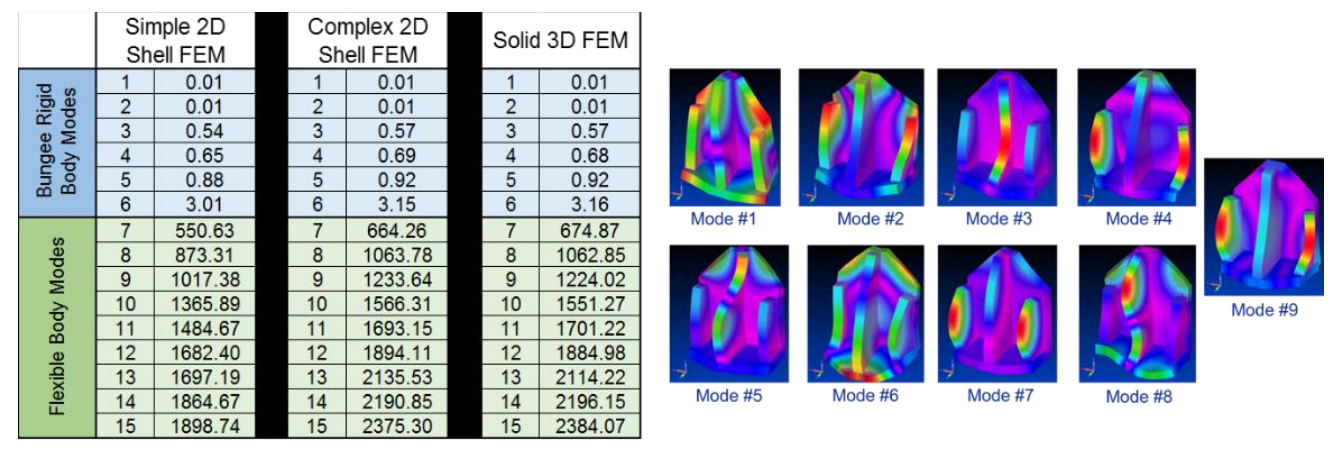

Figure 8. FEM Modal Frequencies and Shape Profiles

An initial set 34 test DOF was utilized the pretest analysis of each FEM. This set was based upon engineering judgement to give the pretest analysis a good starting point for capturing the shape and mas s distribution of the target mode set. The Iterative Residual Kinetic Energy (IRKE) was utilized to identify additional test DOF resulting in a total of 2500 test DOF. Then a down selection algorithm created by ATA engineering was utilized to incrementally remove test DOF to achieve a minimal test DOF set that met the following criteria (numbered by designated importance):

1. $<5 \%$ frequency difference between TAM and FEM fortarget modes

2. $<5 \%$ on off diagonal of the Self-Orthogonality Matrices

3. $>90 \%$ on the diagonal values and $<10 \%$ on off diagonal of the Cross-Orthogonality Matrices

4. $>80 \%$ on the diagonal values Psuedo-Orthogonality Matrices (Used to establis h upper bound only)

The summary tables for each of the pretest analysis of each FEM is shown Table 1. There are two tables shown for each FEM with the Upper Bound being where the Pseudo-Orthogonality criteria is no longer met and the Lower Bound being where the Self-Orthogonality criteria is no longer met. The optimal set of test DOF is between these two bounds and is usually much closer to the Lower Bound. 


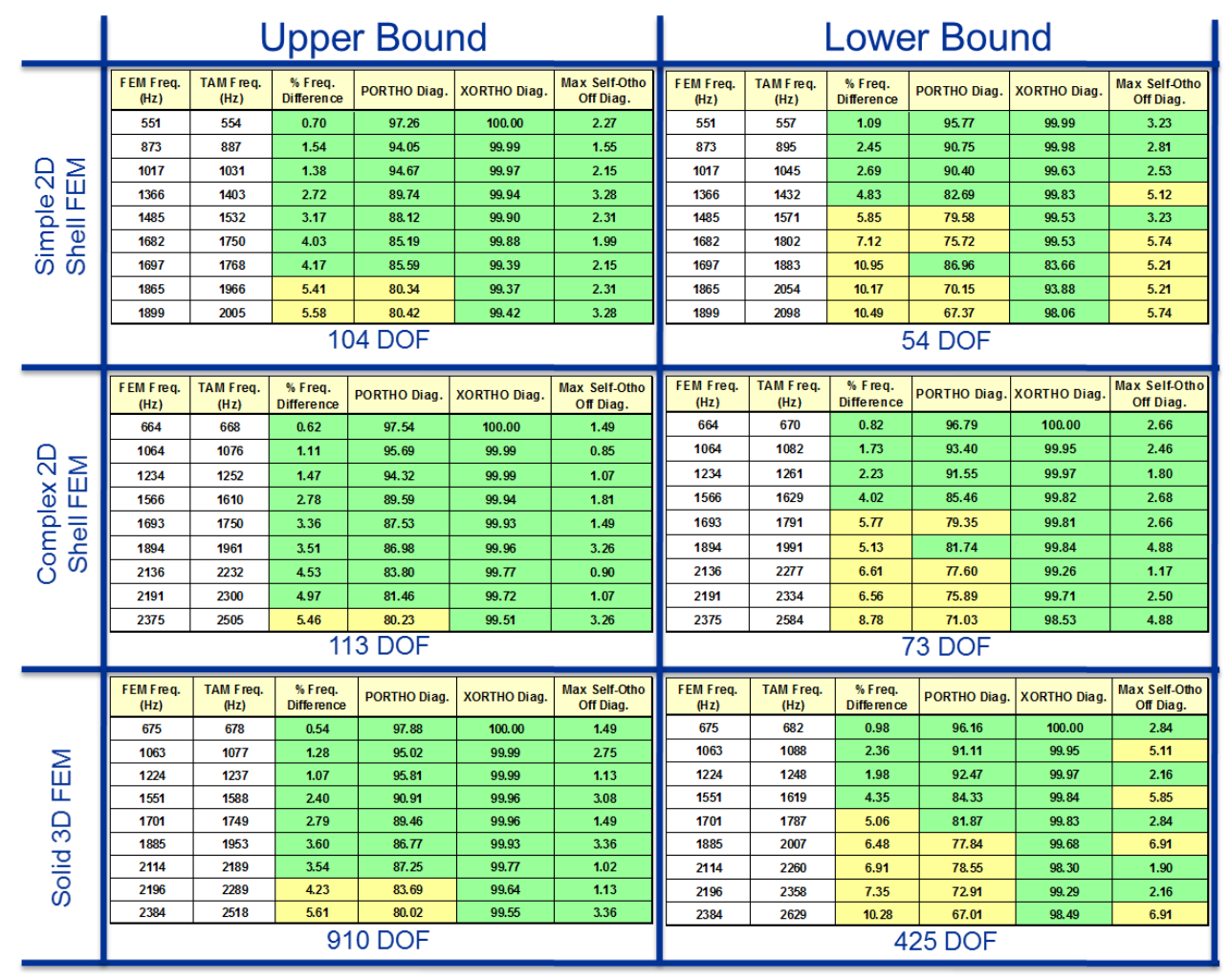

Table 1: FEM Pretest Analysis Comparis ons

This study shows that the use of 3D tetrahedral solid elements is not conducive to this type of sensor selection approach. It should be made clear that for the Solid 3D FEM, the only test DOF the computer was allowed to select were on the external surface. This was done due to the fact that accelerometers cannot be placed inside the test article. It is unders tood that a 2D Shell elements exhibit similar is sues in that the test DOF selected are technically on thecenter line of each surface and can also not be selected, however, all the mass of the FEM is distributed to those same nodes in a 2D shell element. With a solid 3D element, the mass is dis tributed in a much finer fas hion and much more difficult to capture using limited instrumentation. Both the Simple and complex 2D shell FEMs do a reasonable job of selecting an optimized set of test DOF, with the Simple 2D Shell FEM doing a slightly better job.

After seeing these results, it was questioned about whether the appropriate DOF selection method was being utilized or not. Therefore a simple plan to evaluate other DOF selection processes was created and carried out. The flow chart shown in Figure 9 describes this process. 


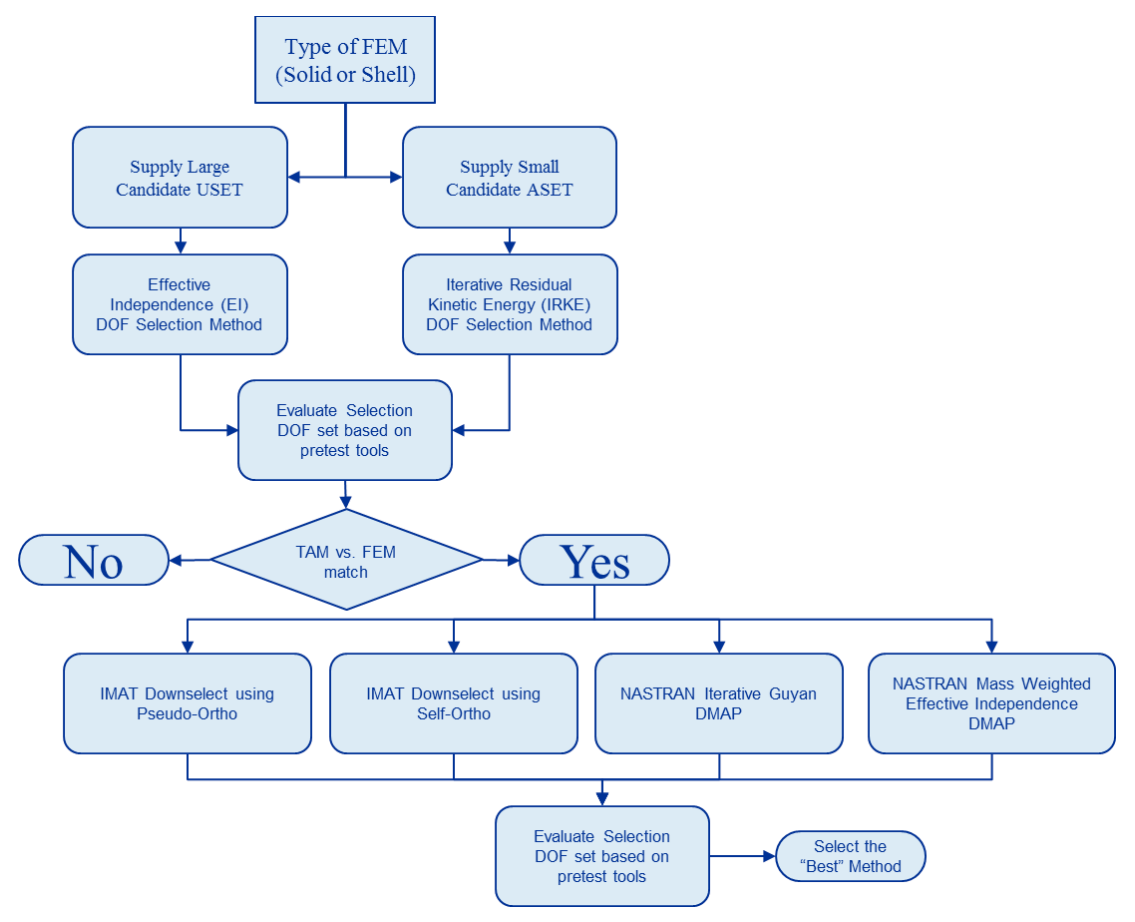

Figure 9. Pretest Analy sis Methodology Evaluation Flow Chart

After finishing this process on all three FEMs, the results clearly showed that the IRKE selection method outperformed the Effective Independence selection method. The other finding was that no matter the method used, the solid 3D FEM always required much higher DOF counts to achieve results within the stated guidelines above. This study served as a good confirmation that the standard way the engineers had been doing pretest sensors selections for past modaltest was indeed the most efficient way to do them.

The final step was to utilize the Simple 2D Shell FEM, which in the studies above showed the best ability to predict an optimal sens or set, to finalize the number and location of the sensors. A set of 75 DOF was selected which met the overall majorit y of the pretest guidelines were met and can be seen in detail in Figure 10.
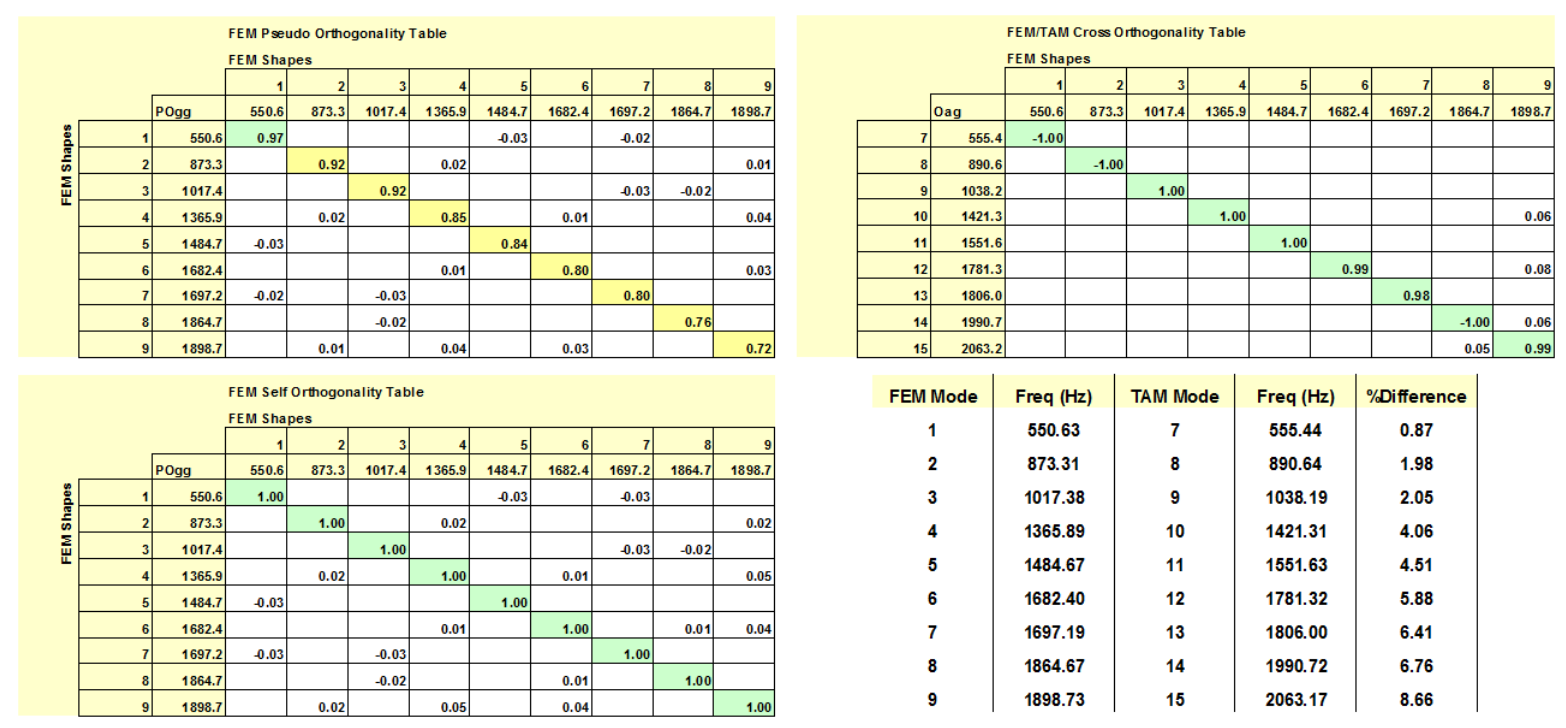

Figure 10. Simple 2D Shell FEM Final Pretest Results 


\section{BOOKEND FREE-FREE MODAL TEST AND MODEL CORRELATION}

The test article was suspended froma soft bungee cord displayed in Figure 11 that resulted in a bounce mode at $\sim 3 \mathrm{~Hz}$ and all of the remaining suspension modes (e.g. $1^{\text {st }}$ and $2^{\text {nd }}$ pendulummodes) below $3 \mathrm{~Hz}$ so that all suspension modes are more than two orders of magnitude below the first flexible body mode.
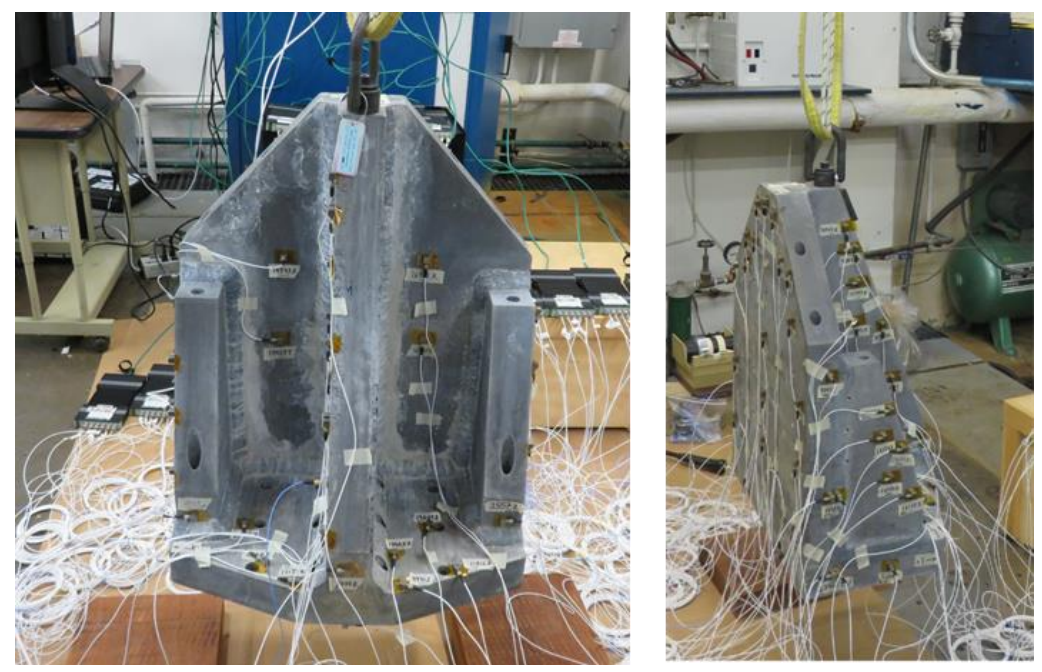

Figure 11. Bookend Free-Free Modal Test Setup

An impact mallet with a hard black vinyl tip was utilized to excite the structure. This tip was able to produce high quality excitation with good coherence up to $1400 \mathrm{~Hz}$ shown in Figure 12. However, the FRFs seem to hold their quality of 2300 Hz. Because this is not an actual test of flight hardware, it was considered acceptable to ignore the guidelines in this specific case and use the modal parameters extracted up to $2300 \mathrm{~Hz}$.

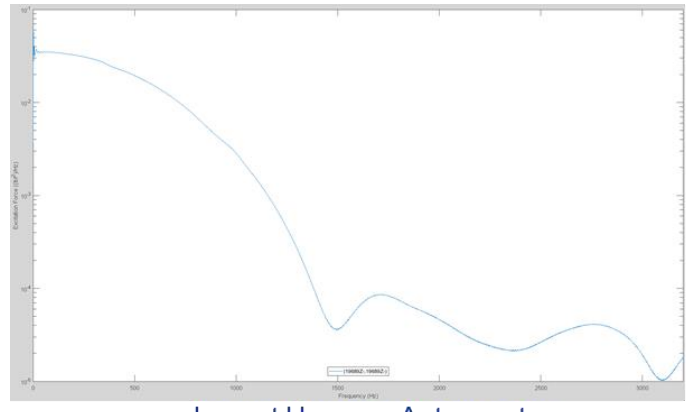

Impact Hammer Autospectra

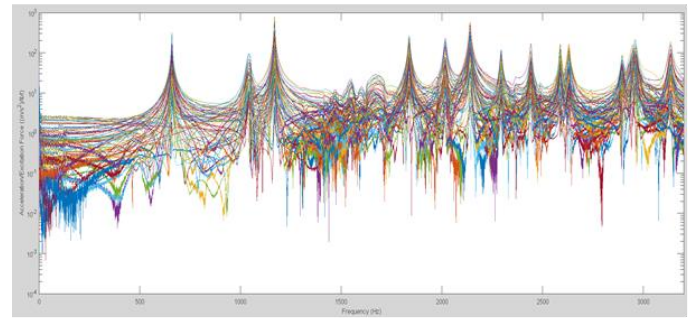

All DOF FRFs

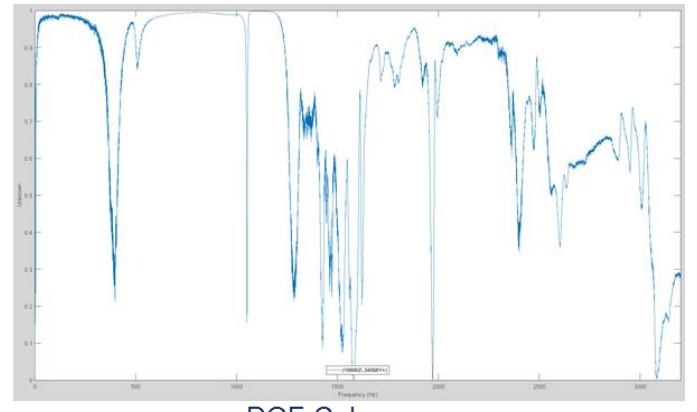

DOF Coherence

\begin{tabular}{|c|c|c|}
\hline Mode \# & Frequency $(\mathrm{Hz})$. & Damping (\%) \\
\hline 1 & 659 & $0.22 \%$ \\
\hline 2 & 1040 & $0.58 \%$ \\
\hline 3 & 1168 & $0.15 \%$ \\
\hline 4 & 1547 & $0.82 \%$ \\
\hline 5 & 1676 & $1.40 \%$ \\
\hline 6 & 1836 & $0.19 \%$ \\
\hline 7 & 2016 & $0.23 \%$ \\
\hline 8 & 2139 & $0.16 \%$ \\
\hline 9 & 2293 & $0.15 \%$ \\
\hline 10 & 2357 & $0.17 \%$ \\
\hline
\end{tabular}

Modal Parameters Extracted

Figure 12. Bookend Free-Free Modal Test Results

Now that test results had been obtained, it was pos sible to determine the answers to the new few questions about which FEM cons truction technique would best predict the actual test results without model updating and the FEM en gineers should continue to utilize going forward in the res earch. 
1. Which model is the most accurate correlation without any model updating?

2. Is modeling in so much detail with the Complex2D Shell FEM required or what subset of modeling features are really neces sary?

3. Which model would be the "best" to use? "Best" meaning a good balance of both accuracy of the hardware while also being user friendly.

The Solid 3D FEM was not able to be included fully in this part of the study because the reduced mas s and stiffness matrices generated using the chosen set of DOF was so insufficient, it corrupted the cross-orthogonality matrices. However, in the figure below, the frequency comparison for the Solid 3D FEM was generated for reference in Figure 13.

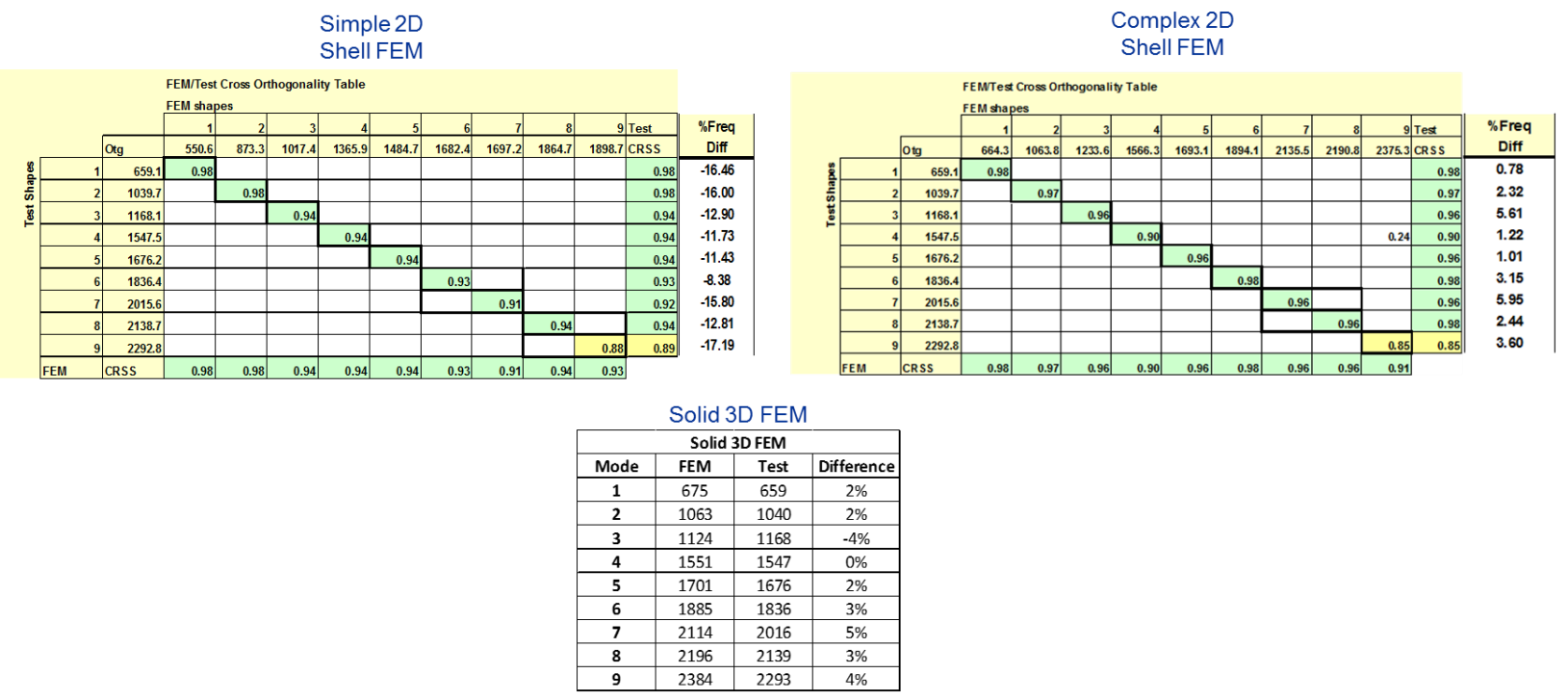

Figure 13. Test vs. FEM Correlation Results for Different FEM Modeling Techniques

One can see the results in Figure 13 that the Complex 2D Shell FEM does the best job predicting the real test results when considering it can be better utilized in a pretest sensor effort. The Solid 3D FEM, as expected, does a very decent job in predicting the results. It only slightly over predicts the stiffness of the test article. The Simple 2D Shell FEM under predicts the stiffness of the model and thus is simulating a test article that is too flexible.

In a normal modal testing effort, test engineers would probably not see a need to update anything with either the Complex2D Shell FEM or the Solid 3D FEM. However, in this research effort it was desired to know what features in the Complex 2D Shell FEM were really necessary. By starting with theComplex2D Shell FEM and slowly removing one complicated feature after another, it was revealed that really only one complex feature, the spider RBE2 elements connecting the plates together, is neces sary in making any 2D shell FEM most accurately simulate real test results. In Figure 14, one can observe the comparison between the starting Complex2D Shell FEM to the much simpler correlated version. 


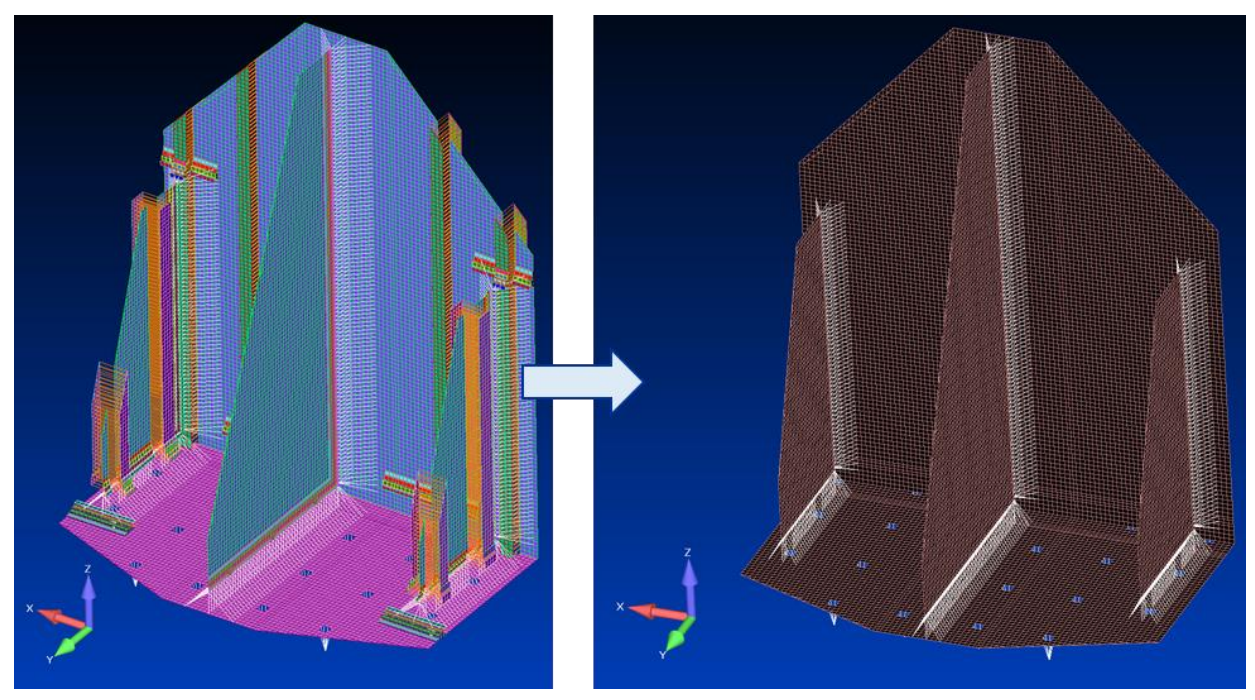

Figure 14. Complex 2D Shell FEM Transition to Simpler 2D Shell FEM

All of the other element offsets and thickness variations that were input to try and capture the true geometry did not seem to make a significant impact, and in some cases, introduced inaccuracies into the FEM. The strain energy plots were a helpful indicator of this inaccuracy which would show discontinuities in the strain energy contour plots at these modeling features. When using this updated much simpler version of the Complex 2D shell model, one can see in Figure 15, that the higher off diagonal value in the cross-orthogonality matrix was actually being generated due to these complicated modeling features.
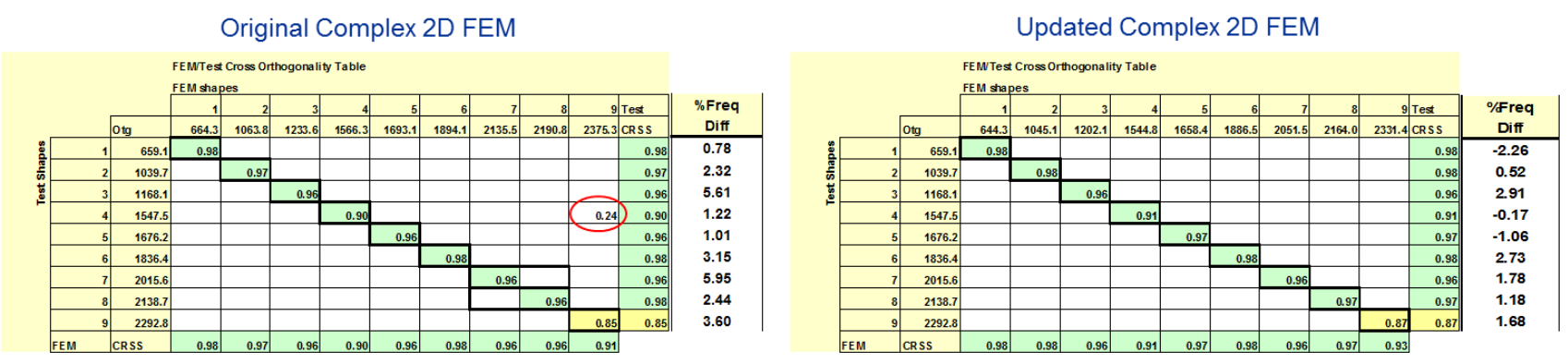

Figure 15. Updated FEM Cross-Orthogonality Comparis on

Based on everything taken into account during these studies, it appears that the bestFEM to use throughout the entire proces $\mathrm{s}$ would be the updated 2D complex FEM where the only complexity is the RBE2 spider at each of the joints. This updated complex 2D FEM is actually not much complicated to construct over the simple 2D FEM. It gives the best predictions without any model updating even occurring which means the technique can be trusted more without the presence of test data. Finally, it allows for a very accurate pretest sensor analysis to be performed. From this point on in the research, only the updated 2D complex FEM will be utilized. It will be referred to as the test article FEM fromthis point on as well.

\section{MULTI-SHAKER SUPPORT SETUP}

In order to correctly utilize the fixed based correction methods, one basic requirement must always be met. There must be an independent uncorrelated excitation source for every shape that is attempting to be removed. The expec tation, based on past studies performed by ATA Engineering [7] on a shaker table, was that the removal of the shaker slip table motion would require at least seven external portable shakers. This meant that en gineers would need to come up with structural supports tohold the portable shakers. The main design requirements of these supports were that they needed to allow for eas y maneu vering of the shakers, allow for adequate height clearances over the slip table, and be cost effective to fabricate. The lab has relied on catwalks spanning over the large shakers that run on tracks at the edges of the building. It was decided to utilize the same tracks and wheel system for this new test capability. The final product dis played in Figure 16 consists of S6 x12.5 standard 
steel I-Beams and manual 1 ton plain trollies attached to 1 ton hand chain hoists which run along the axis of the I-beams. In past experience on fixed based modal testing, engineers have learned that hand chain hois ts are the best option to accurately position the shakers due to their ability to pull large lengths of chain and only move the shakers up or down fractions of an inch. They do not jolt up or down like other electronic cable wenches or chain hoists that have been previously used. Beam clamps were placed on either end of the trolley to hold it stationary once the shakers were located.
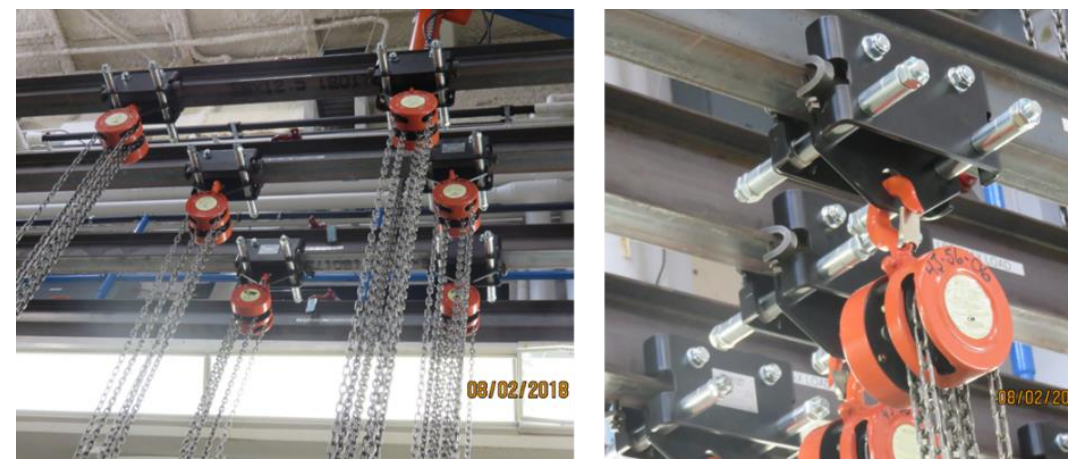

Figure 16. Muti-Shaker Support Beams, Trolleys, and Manual Chain Hoists

To support attachment of the portable shakers to these hoists, a standard lifting hardware setup was created. This lifting hardware setup, shown in Figure 17, consisted of (order from shaker to hoist): s wivel hoist rings fastened to the four corners of the portable shaker trunnions, four-leg cable bridles, and finally a bungee cord link along with a loosely fitted safety strap. The loosely fitted lifting strap was put in place because the bungee cord links were not load tested. Therefore, to ensure s afety, the lifting straps would not allow the shakers to fall if the bungees were to break. Normally, turnbuckles would be used between the $s$ wivel hoist rings and the four-leg cable bridles so that the shaker orientation could be accurately set, however, the lab did not own enough of these for this research and a decision was made to not utilize themin this first phase. Loo king back, they would have been helpful to have and are strongly suggested to be used in the future.
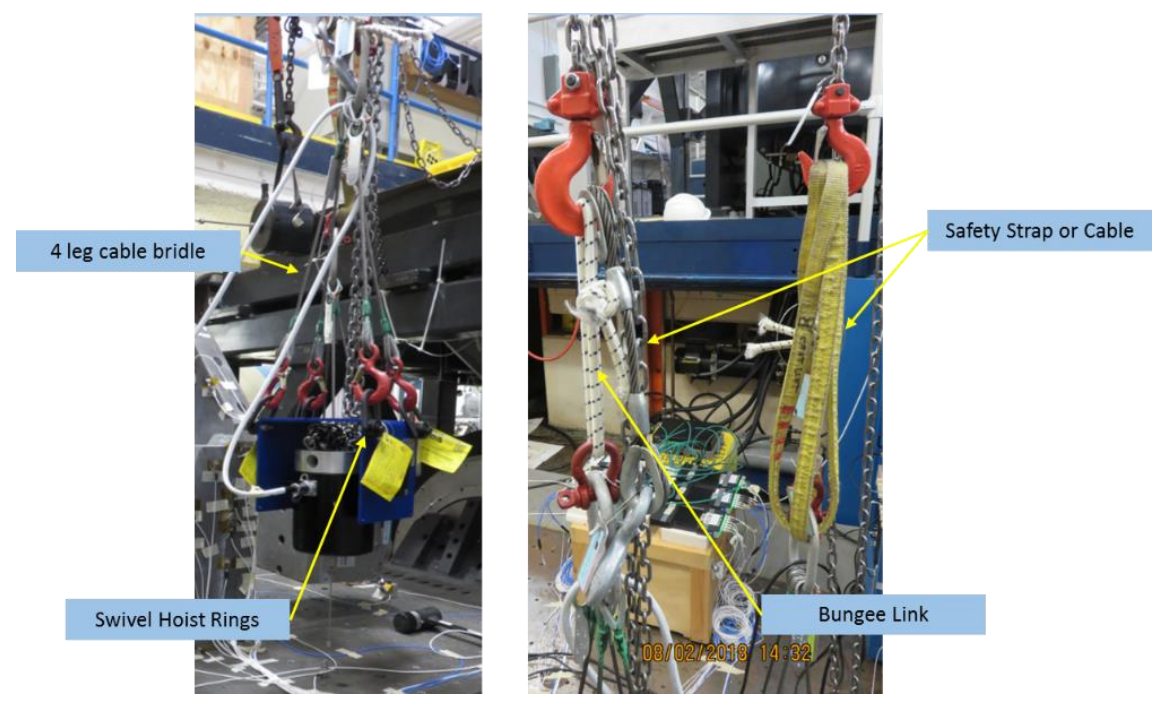

Figure 17. Shaker Support Attachments

\section{TRADITIONAL FIXED BASED MODAL TEST}

The test article FEM that was correlated using the free-free test data documented in previous sections was constrained at all the fas tener locations using RBE2 spiders. The modal analysis was performed to identify thetarget modes that would beextracted in the fixed based testing. Figure 18 shows the frequencies, associated modal effective mass, and the deformation shapes of the selected target modes. 


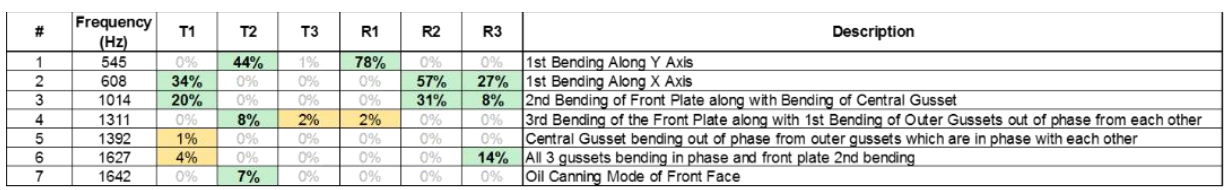

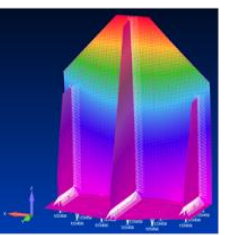

Mode \#1

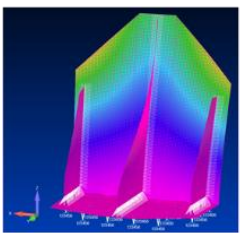

Mode \#2

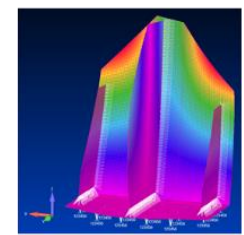

Mode \#3

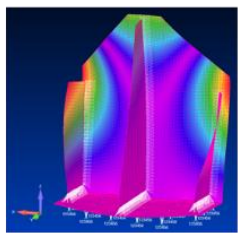

Mode \#4

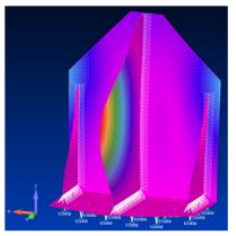

Mode \#5

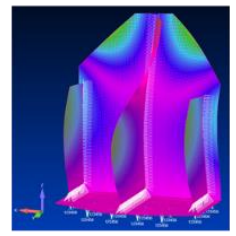

Mode \#6

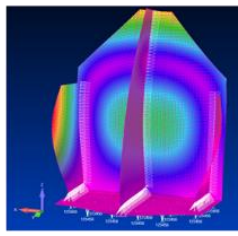

Mode \#7

Figure 18. Bookend Fixed Based Target Modes

It was decided in an attempt to keep things simple to only go after the first seven modes which allowed en gineers to reduce the required instrumentation on the test article from 75 to 53. The final sensor locations can be seen in Figure 19 which also includes the pretest Cross-Orthogonality matrixand frequency differences between thereduced TAM and fullFEM shapes.
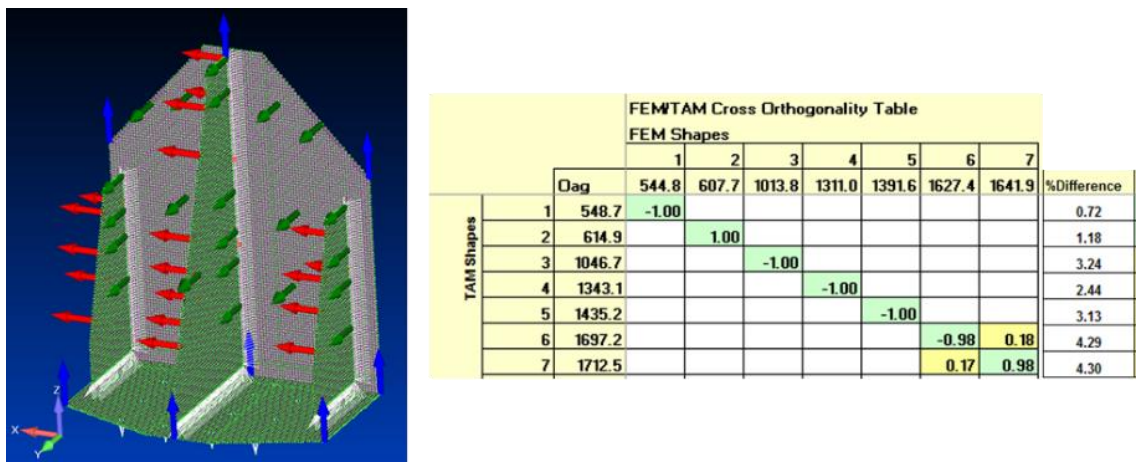

Figure 19. Bookend Fixed Based Modal Testing Pretest Results

It was important to the engineers performing the res earch to have a good baseline of fixed based modal parameters using the traditionally accepted fixed based approach of testing on a seismic mass modalfloor. The lab has a $10 \mathrm{ft} x 10 \mathrm{ft}$ square modal floor that has a 4" x 4" square hole pattern. The test article was bolted down to the modal floor using $3 / 8$ " diameter fasteners that were all torqued to $20 \mathrm{ft}-\mathrm{lbs}$. To be able to accurately capture the modal floor response, accelerometers were installed on the modal floor near the four corners of the test article. Impact hammer testing using a modal mallet with a black vinyl tip was utilized to excite the test article on the modal floor. Impacts were taken on the test article top in all three directions as well as at all four modal floor accelerometer locations. All data was processed using the impact hammer measured force as the reference. The end result of this testing was that the seven target modes were successfully able to be extracted fromthe testing and it showed that significant model updating to the boundary conditions should be performed. Illus trated in Table 2, the RBE2 spider element modeling techniquefixing the base of the test article was much too stiff. 


\begin{tabular}{|c|c|c|c|c|c|c|c|c|c|c|c|}
\hline \multirow[t]{3}{*}{ - } & & & \multicolumn{8}{|c|}{$\begin{array}{l}\text { FEMTest Cross Orthogonality Table } \\
\text { FEM shapes }\end{array}$} & \multirow{3}{*}{$\begin{array}{c}\% \text { Freq } \\
\text { Diff } \\
\end{array}$} \\
\hline & & \multirow[b]{2}{*}{ Otg } & 1 & 2 & 3 & 4 & 5 & 6 & 7 & Test & \\
\hline & & & 544.8 & 607.7 & 1013.8 & 1311.0 & 1391.6 & 1627.4 & 1641.9 & CRSS & \\
\hline \multirow{8}{*}{ 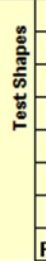 } & 1 & \begin{tabular}{|r|}
394.1 \\
\end{tabular} & 0.96 & 0.24 & & & & & & 0.96 & 38.26 \\
\hline & 2 & 452.3 & 0.26 & 0.94 & & & & & & 0.94 & 34.36 \\
\hline & 3 & 698.0 & 0.23 & 0.30 & 0.89 & & & & & 0.89 & 45.25 \\
\hline & 4 & 1091.6 & & & & 0.95 & & & & 0.95 & 20.11 \\
\hline & 5 & 1271.1 & & & & & 0.93 & 0.22 & & 0.93 & 9.48 \\
\hline & 6 & 1433.1 & & & & 0.31 & & 0.91 & & 0.91 & 13.55 \\
\hline & 7 & 1498.8 & & & & 0.38 & & & 0.88 & 0.89 & 9.55 \\
\hline & FEM & CRSS & 0.96 & 0.94 & 0.89 & 0.95 & 0.93 & 0.91 & 0.88 & & \\
\hline
\end{tabular}

Table 2:Fixed Based Testing Cross-Orthogonality Matrixand Frequency Comparison

The model updating work was chosen to be delayed so that the testing efforts could continue. When looking into theextracted mode shapes, it was discovered that the modal floor was flexing slightly along with the test article. This was completely unexpected as all testing done in the past on the modal floor had never yielded results where the floor appeared to be excited along with the test article. Most aerospace test articles have fundamental resonances well below $400 \mathrm{~Hz}$. However, the fundamental mode of this test article was $\sim 400 \mathrm{~Hz}$. The fixed base correction approach would now have to be applied on the modal floor to remove its influence on the test article, an unexpected challenge that would eliminate the ability to use these results as the baseline in the study. The other thing observed was that the frequency response functions appeared to be "bent" over thus the CMIF was also "bent" over as shown in Figure 20. The pole es timates were generating several of the s ame poles just slightly shifted over in frequency also dis played in Figure 20. This is usually a sign that non-linearbehavior exists. The only explanation to explain this behavior was that the bookend coming up off the floor. The interface stiffness in the vertical up direction is much less than in the vertical down direction where the bookend is in contact with the modal floor. The torqued down $3 / 8$ " bolts are the only thing creating the stiffnessin the up vertical direction.

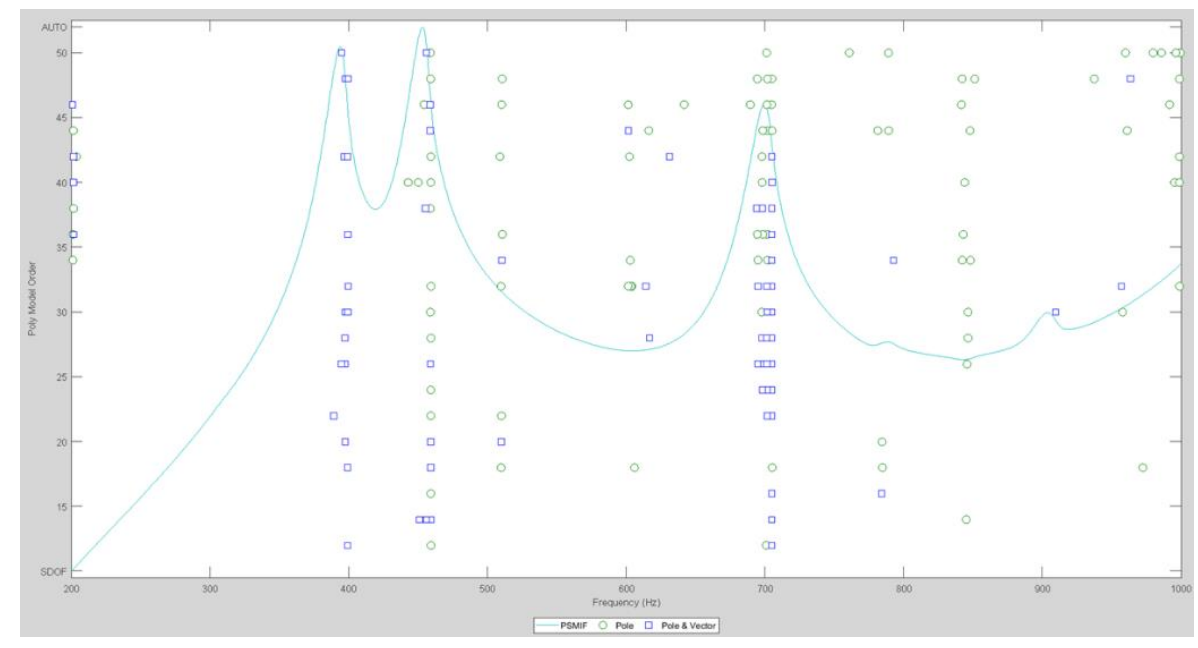

Figure 20. Stability Plot fromFixed Based Modal TestResults

At this point, because the modal floor had not reacted as expected and the test article base appeared to be exhibiting non-linear behavior, an adjustment to the test plan was made. In attempting to addressthe first challenge of the modal floor flexing, multishaker testing on the modal floor was planned out where test engineers would utilize the labs four small portable shakers, exciting three on the modal floor and one on the test article. Refer to Figure 21 for more clarification. 


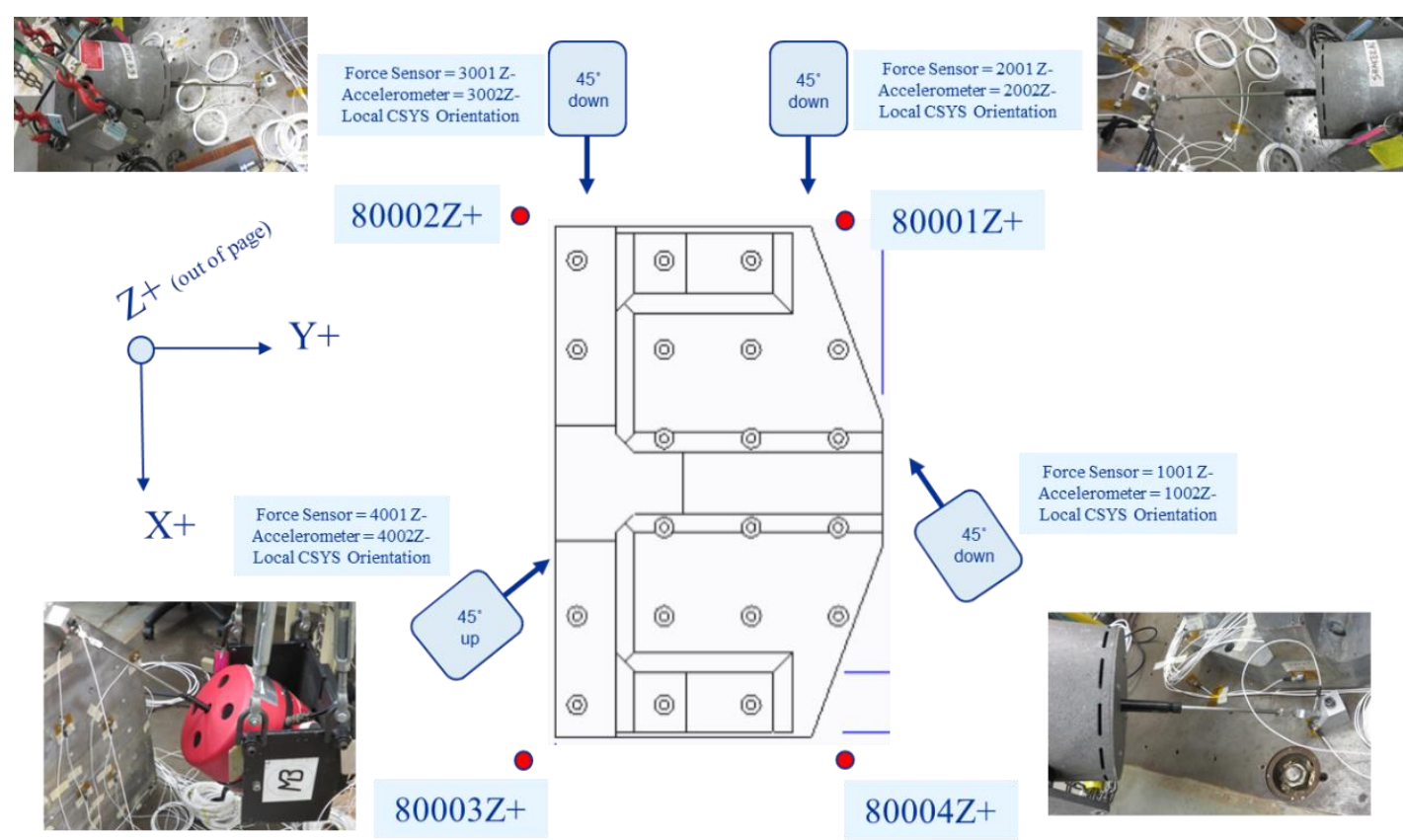

Figure 21. Modal Floor Multi-Shaker Layout

The reason for choosing three shakers on the floor was to allow for the best ability to excite the deformation shapes observed in the extracted fixed based test shapes. There appeared to be three main deformations of the modal floor accelerometers. These deformations can be defined as:

1. All four accelerometers deforming in phase along $\mathrm{Z}$ axis

2. $80001 Z+$ and $80002 Z+$ deforming out of phase relative to $80003 Z+$ and $80004 Z+$ along $Z$ axis

3. $80001 Z+$ and $80004 Z+$ deforming out of phase relative to $80002 Z+$ and $80003 Z+$ along $Z$ axis.

Ideally, test engineers would have liked to drive vertically downward along Z-axis with all three floor shakers. However, it was not possible to drive right next to the test articles vertically because the shaker trunnions would be contactin $g$ the test article. Thus to create enough space to allow the shakers to stay clear of the test articles, 45 degree mounting blocks were used to allow the shakers to drive downward at a 45 degree angle.

The shakers relied on analog filters to bandpass limit the excitation frequency between $200-2000 \mathrm{~Hz}$. Through previous testing experience, these analog filters have been utilized to at least limit the lower frequency range as much as possible to minimize shakerbouncing to protect themagainst over stroking when suspended. The frequency response functions shown in Figure 22 using the three floor shakers as references and the four modal floor accelerometers as references clearly show dynamic response in the floor taking place. 


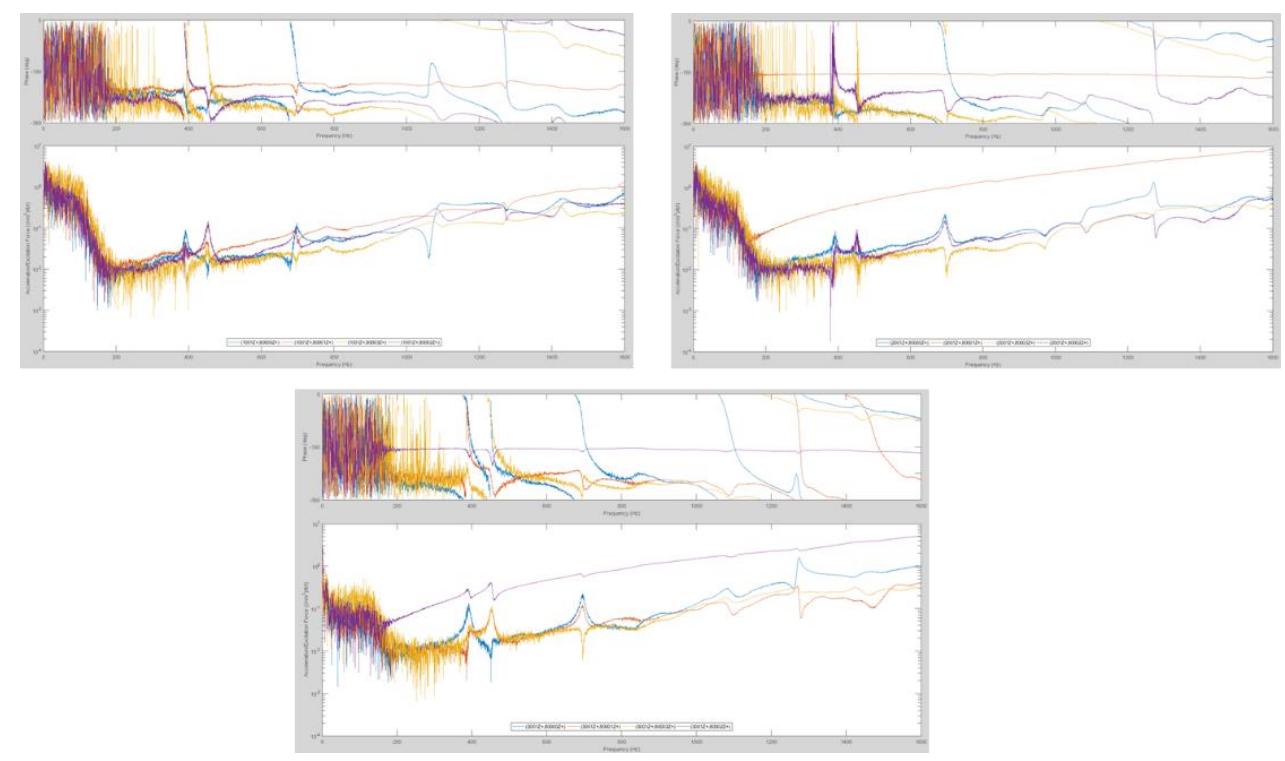

Figure 22. Frequency Response Functions of Modal Floor Accelerometers (Res ponses)/Modal Floor Shakers (References)

Using the three shaker drive points as references, new FRFs were generated that would remove the motion of the modal floor from the test article. This was completed using two different approaches. First, the FRFs were calculated using the shaker forces as references, then the references were switched out using the Structural Modification Using (Frequency) Response Function (SMURF) approach that was coded into the IMAT software by Kevin Napolitano of ATA Engineering. This technique rearranges the FRF matrix by replacing the current references with new references through a partial inversion of the FRF matrix [11]. The second approach used, referred to as Drive Point (DP in Figure 23), was simply us ing the shaker drive point accelerometers as references in the formulation of the FRFs. Modes were extracted from the FRF created from both correction techniques and compared back to the uncorrected modal parameters. This showed that the effect of the floor compliance (although minimal) was successfully able to be removed using either technique utilized.

\begin{tabular}{|c|c|c|c|c|}
\hline Uncorrected & \multicolumn{2}{|c|}{ SMURF Corrected } & \multicolumn{2}{c|}{ DP Accels Corrected } \\
\hline Freq (Hz) & Freq (Hz) & $\%$ Diff & Freq (Hz) & $\%$ Diff \\
\hline 394 & 401 & $2 \%$ & 400 & $1 \%$ \\
\hline 452 & 463 & $3 \%$ & 461 & $2 \%$ \\
\hline 698 & 709 & $2 \%$ & 706 & $1 \%$ \\
\hline 1089 & 1098 & $1 \%$ & 1095 & $1 \%$ \\
\hline 1275 & 1282 & $1 \%$ & 1279 & $0 \%$ \\
\hline
\end{tabular}

Figure 23. Fixed Based Modal Frequency Comparison Table

More testing was desired to be performed with the shakers on the modal floor to allow engineers to determine if more torque on the fasteners would help reduce the effect of the non-linear behavior at the base of the bookend, but due to time restraints, it was decided to move onto the shaker slip table testing and if time permitted at the end, the test article could be retumed to the modal floor to inves tigate that further.

\section{SHAKER SLIP TABLE MODAL TEST}

The bookend with its instrumentation installed was transferred as a unit onto the shaker slip table interface next. The shaker support beams and shakers were then positioned into place around the shaker slip table. The lab didn't own the quantities of portable shakers and signal generators required to perform the objectives of this slip table test. The plan was put into place to get a short termrental of the shakers fromThe Modal Shop and supplement the current signal generators currently owned by the lab by renting the extra LAN-XI 3160 modules from Bruel and Kjaer. The shaker layout was first setup to allow for the 
removal of the 6 rigid body modes of the slip table from the test article. The large electrodynamic shaker was disconnected from the slip table to start off with. It was intended to utilize the large shaker as one of the independent excitation sources in this first stage of the research, but time did not allow for it. It is planned to be utilized in testing going forward in th is res earch investigation. For the first tests, the slip table oil was turned on to allow for free motion. The layout of the shakers and instrumentation can be seen in Figure 24.
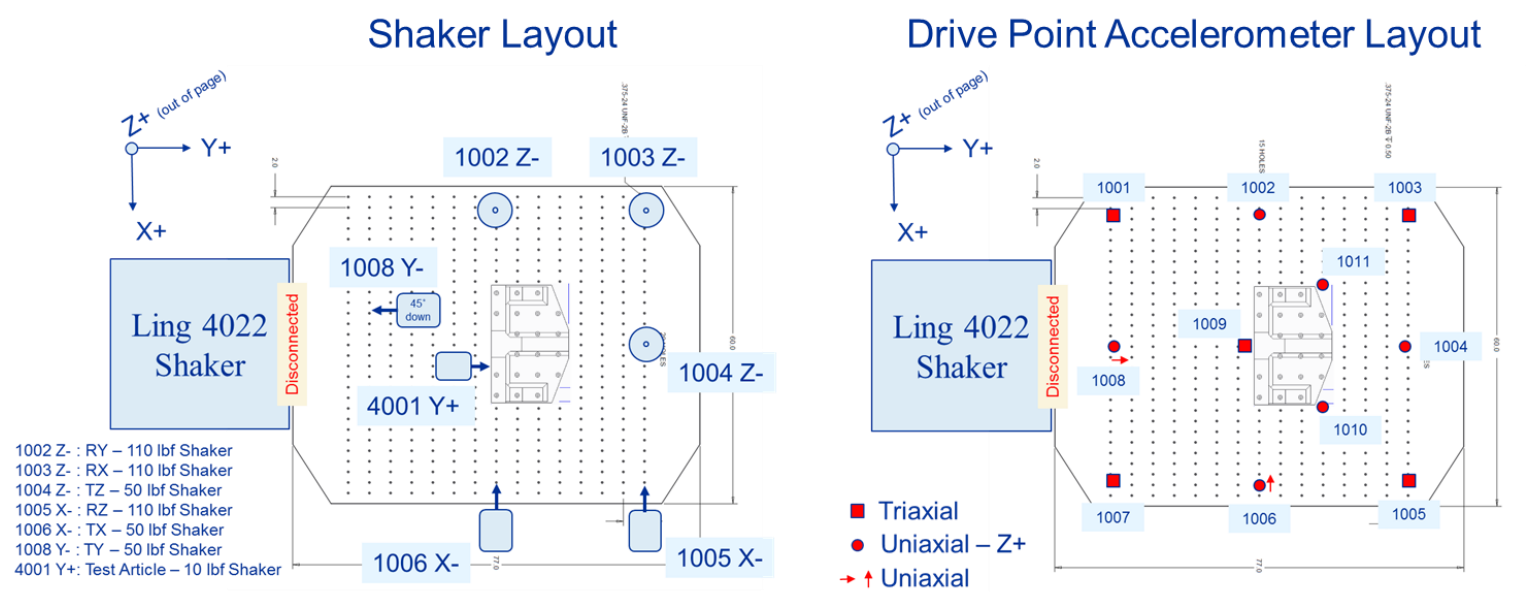

Figure 24. Shaker Slip Table Multi-Shaker Layout

The shakers were analog band pass limited from $15 \mathrm{~Hz}-800 \mathrm{~Hz}$. They were all run at the same forcing level with the exception of the shaker on the test article which was too s mall to achieve the same force level. In addition, multi-s haker data was also taken with the slip table oil off. Test en gineers made the decision early on to take data on as many different test config urations as they could think of during the rental period of the shakers and extra LAN-XI modules. This put on hold any data processing and review until after all the testing was complete. This was definitely not theideal way to carry this out, but it was extremely important to test engineers to get data on as many different configurations as they could think of while they had theequipment available.

After all the multi-shaker testing was completed, additional test configurations were collected on the shaker table utilizing impact hammer testing at all the drive point accelerometer locations. This was done to see if in the data processing, all the impacts could be concatenated and then processed as if they were all performed in the same test. It was desired to see if this testing would generate similar results to the multi-s haker testing. Another test configuration that was performed was to move all the accelerometers positioned on the slip table next to the test article as opposed to the edges of the slip table. This was done to see if better results could be obtained by only removing motion close to the test article as opposed to the entire slip table interface. In all 85 different tests, shaker and impact hammer, were carried out during this first phase of the res earch effort.

\section{FUTURE WORK}

It is important that the reader understand that this work was simply the first phase of what potentially could be a three phased research effort. The first goal of the second phase will be to process and analyze all the collected data from the test runs performed in this first phase and be able to determine what test configurations worked best at removing the base motion on the slip table. There is a concern about the test article chosen being too stiff and not really accurately simulating traditional aeros pace structures. The stiffer the test article, the more modes the slip table will have influencing the test article base. Very preliminary inves tig ation into the data shows that the final slip table rigid body mode occurs almost $150 \mathrm{~Hz}$ below the first test article mode. For every additional mode in the slip table above the last rigid body mode another shaker would need to be added to remove that influence from the test article. This concern might turn out to drive a test article change to one that is more representative of a realistic aerospace structure. Another concern that needs to be sorted out before going much further is if torqueing the fas teners down higher than the typical NASA standard would help linearize the base of the bookend. Once these 
current unknowns are sorted out and the findings of the data documented, then engineers would like to develop a test approach for utilizing the large electrodynamic shaker as one of the independent uncorrelated inputs into the shaker slip table. The first step would be to try this at low levels of excitation. If this works, then it would be desired to increase the drive level of the large electrodynamic shaker and see if it would be possible to shake at flight random vibration test levels while exciting fixed based modes at the same time. Most of this described testing work would be carried out in the third phase of the research.

\section{SUMMARY}

Based on the limited data that has been reviewed and processed up to the point of writing this paper, there is confidence that several fixed based correction options can be employed on the vast array of test data collected during this initial phase of the research effort. The trade studies performed on the simple beam were invaluable in helping get s tarted in utilizing these methods and developing the basic understanding. More will be done with that test data to further enhance the understanding of the fixed based correction methods and their limitations. The trade studies performed utilizing different techniques of cons tructing FEMs was extremely helpful to first reassure test en gineers that the pretest sensor selection methods they had been utilizing are the most efficient in addition to defining the best modeling technique that will be utilized going forward on this research. Finally, the les sons learned in setting up the infras tructure to support multiple shakers and driving themin a MIMO test effort will tran slate outside of this research study into all MIMO testing the lab performs in the future. Engineers understand that they have simply started to scratch the surface with this testing of what could be possible going forward and that a lot of work still remains in the process.

\section{ACKNOWLEDGEMENTS}

A special thank you to Kevin Napolitano and Elliot Haag of ATA Engineering Inc. for providing engineering support and guidance throughout this initial phase of the research effort.

\section{REFERENCES}

[1] Carne, T.G., D.R. Martinez, and A.R. Nord. "A Comparison of Fixed-Base and Driven Base Modal Testing of an Electronics Package." Proceedings of the Seventh International Modal Analysis Conference, 1989: 672-9.

[2] Beliveau, J.G., F.R. Vigneron, Y. Soucy, and S. Draisey. "Modal Parameter Estimation fromBase Excita tion.” Journal of Sound and Vibration 107. 1986: 435-49.

[3] Fullekrug, U. "Determination of Effective Masses and Modal Masses from Base-Driven Tests." Proceedings of the 14th International Modal Analysis Conference, 1996: 671-81.

[4] Sinapius, J.M. "Identification of Fixed and Free Interface Normal Modes by Base Excitation." Proceedings of the 14th International Modal Analysis Conference, 1996: 23-31.

[5] Mayes, R.L., and L.D. Bridgers. "Extracting Fixed Base Modal Models from Vibration Tests on Flexible Tables." Proceedings of the $27^{\text {th }}$ International Modal Analysis Conference, 2009.

[6] Napolitano, K., and N. Yoder. "Fixed Base FRF Using Boundary Measurements as References - Analytical Derivation." Proceedings of the $30^{\text {th }}$ International Modal Analysis Conference, 2012.

[7] Napolitano, K., N. Yoder, Fladung, W. "Extraction of Fixed-Base Modes of a Structure Mounted on a Shake Table." Proceedings of the $31^{\text {th }}$ International Modal Analysis Conference, 2013.

[8] Staab, L. J. Winkel, V. Suárez, T. Jones, and K. Napolitano. "Fixed Base Modal Testing Using the Mechanical Vibration Facility 3-Axis Base Shake System." Proceedings of the $34^{\text {th }}$ International Modal Analysis Conference, 2016.

[9] Napolitano, K., J. Winkel, J. Akers, V. Suárez, and L. Staab. "Fixed Base Modal Survey of the MPCV Orion European Service Module Structural Test Article." Proceedings of the $36^{\text {th }}$ International Modal Analysis Conference, 2018.

[10] Napolitano, K. (2017, November 14). Personal interview with James Winkel.

[11] Crowley J.R Klosteman A.LRockin,GJ. And Vold.H. "Direct structural modification using frequency response functions" Proceedings of the $2^{\text {nd }}$ Internationalmodal analysis conference, 1984. 